But when you are called to see a case that a general practitioner has been treating with atropine for a week under the assumption that iritis was the condition when it really was glaucoma, you are certainly justified in considering that you have wiped the G.P.'s eye. It is unfortunate if those in general practice who have had no special training in ophthalmology get the idea that atropine drops can be used indiscriminately in ophthalmology. It would be much better if they would confine their prescriptions to simple boracic lotion and call in a consultant early.

\title{
CORRESPONDENCE
}

\section{SOLAR RETINITIS}

To the Editors of The British Journal of Ophthalmology.

DEAR SIRS,-The article on "sclar retinitis' by Emanuel Rosen which appeared in your January number is a notable contribution to this subject, and will probably interest those of your readers familiar with cases of solar injury as much as it interested me. The outstanding feature of the article is the observation that one or more holes at the macula were noted in a series of 23 cases of solar injury tabulated in detail, and that holes at the macula were seen in over 500 undetailed cases of coloured troops "every one of whom was exposed to the direct action of the sun's rays."

Many other interesting points are evoked, however, some of which you may perhaps allow me to raise here, viz.:

1. Has the author seen many cases in which the typical early appearances resulting from sun-gazing, direct or indirect, was not followed by an actual hole, and in which complete recovery apparently took place?

2. What is the frequency with which the typical appearance of the sun-gazer's macula (such as described by Kirkpatrick in Elliot's Tropical Ophthalmology and quoted at length by Dr. Rosen), occurs when the unprotected eye is exposed to prolonged tropical glare when "working out of doors, etc.," but not subjected to direct sun rays or rays reflected from a glazed surface? H. E. Smith, quoted by the author, seems to consider such a sequence of events is relatively frequent.

3. What are the similarities and differences in early and late appearances between the typically produced sun injury at the macula, and the so called central serous and central angiospastic retinopathies, supposed to be associated with disturbances of the autonomic nervous system? Is the immediate effect of the sun 
injury a minute serous or haemorrhagic bleb which takes a variable time to burst (or absorb without bursting), and the late effect ordinarily a hole?

4. If a hole at the macula following solar injury is relatively common in tropical and subtropical environments, and it probably is, what is the frequency with which it is followed by detachment of the retina?

5. To what extent are dark skinned races less liable to sun injury at the macula?

6. Why do some individuals escape who look directly into the sun again and again in the course of practising a religious rite, or of performing a duty such as taking an observation on the sun at sea, whether they be fair skinned or dark skinned, whilst others suffer the characteristic damage?

It would require access to many case records and to a voluminous literature to discuss profitably some of the questions asked above, and go far beyond my first intentions in writing this letter. I shall therefore content myself with a few remarks, and opinions based for the most part on memory.

If a hole (or holes) at the macula is as frequent a sequel to the sun-gazing trauma as Dr. Rosen's observations indicate, why has the positive diagnosis of hole not been made more often in tropical ophthalmic clinics, and in the clinics of other countries after eclipses? The reason I think is, that in order to be quite certain that the sharply marked maroon coloured spot is or is not a hole, it is essential to employ adequate specialised illumination. Dr. Rosen used retro-illumination (method of Friedenwald). Vogt, by means of red-free light, determined details at the macula previously unobserved. Elliot knew that a hole might occur, so did Kirkpatrick, yet in the Madras Ophthalmic Hospital the usual diagnosis of the typical lesion was, "sun injury at the macula" or some such. I was seldom quite satisfied that a solar trauma had produced a hole until, shortly before leaving Madras in '37, I started using the Friedenwald hand ophthalmoscope with slit illumination and filters. The ordinary British hand ophthalmoscopes used in routine work were unequal to the exhaustive clinical examination of macular detail. I imagine that with suitable apparatus and illumination the diagnosis of hole at the macula would often augment that of solar injury, by obviating dependence on parallax.

With regard to (1) above my opinion is that complete recovery of vision and complete (?) normality of macular appearances may follow a typical sun-gazer's macula with diminished visual acuity and central scotoma. Complete is queried since the observations on which this opinion is founded were made with the ordinary electric ophthalmoscope. In considering (2), one must be very careful to avoid introducing a fallacy. After a considerable experience of the fundus 
appearances met with in South India, both in Europeans and Indians whose eyes were unprotected from tropical glare, I do not remember having seen a case of sun-gazer's macula in which exposure to direct sun rays, or sun rays reflected from a glazed surface, was excluded. The possibility of the injury being caused by rays reflected from sheets of water such as one finds in the paddy fields of South India was well recognised; but there are very many other ways in which an indirect solar injury may be caused. One case (records 1924), which eluded me at first, was that of a surveyor who took a bearing on a heliotrope with a theodolite. I shall be surprised if a good case is made out for the thesis of $\mathrm{H}$. E. Smith to which the author alludes, if $I$ interpret this correctly from his reference.

A consideration of (3) would lead us too far afield.

With regard to (4), a prolonged follow-up of cases would be necessary to determine this point. Detachment following hole at the macula, however, is sajd to be rare whatever its aetiology. I cannot remember seeing a detachment associated with sun injury at the macula ; but then I have seen relatively few Europeans with this affection, and my impression is that detachment of the retina, from whatever cause, is much more uncommon in the Indian eye.

The answer to (5) requires two strictly comparable series of figures, which are not at my disposal. In considering (6), the duration of exposure is presumably very important. Possibly the refraction plays a part. I formed impression that myopes were less liable to sun injury at the macula, but have no records to support this. In a series of 21 cases which I published with Dr. Venkatarangum Nayudu after the 1922 eclipse no record was made of the refraction, and since then the detailed records of my cases are not available. Dr. Rosen's series shows a preponderance of hypermetropes.

Dr. Rosen considers that the danger of solar injury is not sufficiently reconnised by the medical profession and the community at large. This is probably true for certain parts of the world, but even in those part's of the tropics where sun-gazing is practised as a religious rite or takes place unintentionally during agricultural employment, and is relatively common and well recognised, the damage to sight does not appear to be so severe as to place it amongst the more important causes of preventible amblyopia. It would probably be a great mistake for the average European to become too glare conscious when living in the tropics and for the ophthalmologist to overstress the risk of sun injury, however attentive to the comfort and idiosyncrasies of the individual patient perturbed by conditions associated with excessive light.

Yours sincerely,

ROBERT E. WRIGHT.

Fleet, Hants.

February, 7, 1948. 